\title{
Semen assessment, fertility and the selection of Hereford bulls for use in $\mathrm{AI}^{*}$
}

\author{
P. D. P. Wood§, J. A. Foulkes $\dagger$, R. C. Shaw and D. R. Melrose $\ddagger$
}

Milk Marketing Board, Thames Ditton, Surrey KT7 OEL; †Ministry of Agriculture, Fisheries \& Food, Cattle Breeding Centre, Shinfield, Reading RG29BZ; and $\ddagger$ Meat and Livestock Commission, Bletchley, Milton Keynes MK2 2EF, U.K.

\begin{abstract}
Summary. Nineteen young Hereford bulls were used to study the relationship between semen characteristics and fertility in artificial insemination following 15320 inseminations. Seven measures of sperm motility, morphological abnormalities, the release of hyaluronidase, ATP content and sperm head measurements were examined as predictors of fertility (49-day fixed-interval non-return rate). Two assessments of motility, three categories of abnormal spermatozoa, acrosomal changes and the release of hyaluronidase had predictive power. Multiple regression analysis showed that a combination of sperm motility after dilution in saline, motility after thawing and the proportion of coiled tails and proximal protoplasmic droplets provided the best prediction of fertility and allowed bulls to be ranked in order of observed non-return rate $(\%)$ with a Spearman correlation better than $+0 \cdot 80$.
\end{abstract}

\section{Introduction}

A major proportion of animals reared for beef in the United Kingdom arise from the use of beef bulls in the national dairy herd. Beef bulls for use in artificial insemination (AI) in the U.K. are obtained from MLC Performance Testing Stations after they have shown superior growth rates up to 400 days of age. Many such bulls have, however, been rejected on the basis of their semen quality as assessed in the laboratory, with a consequent loss of potentially valuable genetic material.

Laboratory evaluation of semen from a variety of breeds has been shown to identify semen of low fertility (Linford, Glover, Bishop \& Stewart, 1974). The percentage of spermatozoa with proximal protoplasmic droplets was valuable in identifying immature spermatozoa and, when used with estimates of sperm motility, provided useful information on the fertility of individual ejaculates. It was concluded, however, that all 13 tests examined in that study were poor predictors of fertility and that to exclude ejaculates of low fertility semen of adequate fertility was being discarded. This being the case, it was of interest to show the extent to which the apparent semen quality of the bulls being rejected for AI was reflecting their potential fertility. Since Hereford bulls are used for the majority of cross-breeding for beef in the predominantly Friesian/Holstein dairy herd in the U.K. additional information on the correlation between traits used to indicate semen quality and Hereford bull fertility was sought in this trial.

\section{Materials and Methods}

Bull selection and management

The 19 Hereford bulls were obtained from MLC Performance Testing Stations. They were

* Reprint requests to Dr J. A. Foulkes, MAFF, Cattle Breeding Centre, Shinfield, Reading RG2 9BZ, U.K. $\S$ Deceased. 
selected solely on growth rate and conformation and were included in this study if they were able to serve into an artificial vagina (AV) and provide a maximum of $20 \times 10^{8}$ spermatozoa in an ejaculate. The bulls entered the semen assessment trial at 13-18 months of age. The bulls were maintained in standings at the MAFF Reading Cattle Breeding Centre and fed a ration of mineralized concentrate $(1.8 \mathrm{~kg} /$ day $)$, rolled barley $(1.4 \mathrm{~kg} /$ day $)$, grass wafers $(1.4 \mathrm{~kg} / \mathrm{day})$ and hay $(4.5 \mathrm{~kg} /$ day $)$. The composition of the diet was monitored by chemical analysis and determination of feeding value and mineral and trace elements.

Records were kept of the temperature and humidity in the standings to allow comparison of the effects of extremes on fertility. The bulls were maintained at the Centre for a minimum of 10 months and their growth and condition were monitored by weekly recording of their weight and by monthly measurement of testicular circumference and assessment of epididymal shape and consistency. Every 4 months the height-to-withers was noted and the circumference of the cannon bone at its narrowest point was measured. At the same interval, a blood sample was taken from the tail vein and blood glucose, copper, zinc and packed cell volume were determined. All treatments, including sheath lavage, mange-washing and foot-trimming were noted and a health record kept throughout the period of study.

\section{Semen collection and processing}

Two ejaculates were collected from each bull on one day each week using an artificial vagina and graduated test tube. Altogether, 647 first and 646 second ejaculates were obtained. The semen was immediately transferred to a water bath at $30^{\circ} \mathrm{C}$ and all manipulations were conducted using warmed glassware. Since the volume of the ejaculates varied and was frequently low, not all laboratory tests were conducted on all samples collected. All samples were coded by bull, date of collection and ejaculate number. Each month a collection date was chosen at random for processing semen for use in the field trial. Ejaculates with a volume and density sufficient both for conducting laboratory tests and producing the 40 straws necessary for distribution to inseminators were used in the field trial. When insufficient semen was produced, semen collected from the same bull the following week was used. Since the second of two ejaculates was less commonly capable of supplying sufficient semen, fewer second ejaculates were used in the field trial. Suitable ejaculates were diluted in lactose-egg yolk-glycerol diluent to provide $20 \times 10^{6}$ spermatozoa in each $0.25 \mathrm{ml}$ polyvinylchloride straw before freezing and storage at $-196^{\circ} \mathrm{C}$ (Foulkes, Goodey \& Stewart, 1977).

\section{Semen assessment}

With the exception of measurements of volume and density, all semen assessment procedures were conducted after random coding of ejaculates to ensure that operators were unaware of the bull from which semen was taken. The volume of each ejaculate was noted. Samples $(0.20 \mathrm{ml})$, diluted in $14.8 \mathrm{ml}$ trisodium citrate $2 \mathrm{H}_{2} \mathrm{O}(3.6 \% \mathrm{w} / \mathrm{v})$, were used to determine sperm density in an Eel colorimeter which had been previously calibrated with standards whose sperm density had been estimated with a haemocytometer (Cox \& Melrose, 1953).

\section{Motility determinations}

Ejaculated semen $(M I)$. Samples of ejaculated semen $(0 \cdot 1 \mathrm{ml})$ were placed on a warm slide $\left(40^{\circ} \mathrm{C}\right)$ under a coverslip and examined independently by two observers using a microscope ( $\times 160$ ). The motility was scored on a scale of $0-10$, based on the presence of wave motion and its vigour and intensity.

Ejaculated semen diluted in saline (M2). A further sample $(0.1 \mathrm{ml})$ was diluted with 19 volumes sodium chloride solution $(0.85 \% \mathrm{w} / \mathrm{v})$ and similarly examined. The percentage of cells showing progressive forward motility was estimated. 
Frozen and thawed semen (M3). When ejaculates were used in the field, two straws which had been frozen for a minimum of $24 \mathrm{~h}$ were taken from liquid nitrogen $\left(-196^{\circ} \mathrm{C}\right)$ and thawed by immersing in a water bath at $30^{\circ} \mathrm{C}$ for $10 \mathrm{sec}$. A sample $(0.1 \mathrm{ml})$ was taken from each straw, examined under the microscope at $40^{\circ} \mathrm{C}$ as before and the percentage of cells showing progressive forward motility was assessed.

Frozen and thawed semen diluted in citrate (M4). Two additional straws were thawed and the diluted semen $(0.25 \mathrm{ml})$ was rediluted with trisodium citrate. $2 \mathrm{H}_{2} \mathrm{O}(3.0 \% \mathrm{w} / \mathrm{v} ; \mathrm{pH} 7.0 ; 0.75 \mathrm{ml})$. The semen was examined as before and the percentage of cells showing progressive forward motility was assessed.

Motility recovery after shearing semen (M5). Two samples $(0.2 \mathrm{ml})$ of ejaculated semen were taken and examined at $37^{\circ} \mathrm{C}$ using a 'motility meter' (Glover, 1968). Four measurements were made in each sample of the time taken for the pattern of wave motion in the semen to be re-established after disruption by the application of a shearing force.

Photographic estimation of motility before (M6) and after (M7) freezing. Three aliquants of each ejaculate diluted in lactose diluent for use in the field and cooled to $5^{\circ} \mathrm{C}$ were taken $(0 \cdot 1 \mathrm{ml})$ and further diluted with two volumes of trisodium citrate. $2 \mathrm{H}_{2} \mathrm{O}(2.9 \%, \mathrm{pH} 6.9)$ to provide a prefreezing control (M6). Three straws prepared from each ejaculate were thawed after freezing and storage in liquid nitrogen at $-196^{\circ} \mathrm{C}$ and similarly diluted in citrate solution (M7). An aliquant $(5 \mu \mathrm{l})$ of each sample was pipetted on to a clean, warm slide and a coverslip placed over the sample without trapping air bubbles. The slide was transferred to a heated microscope stage and equilibrated at $30^{\circ} \mathrm{C}$ for $30 \mathrm{sec}$. Two $1-\mathrm{sec}$ exposures were made of separate fields from each preparation using the $\times 25$ objective with a dark background. The film was developed and the total number of spermatozoa in the frame counted on the negative. The proportion of motile spermatozoa was determined from the number of tracks left by moving spermatozoa (Katz \& Dott, 1975).

\section{Adenosine triosephosphate (ATP) content}

Samples of ejaculated semen $(1 \mathrm{ml})$ were centrifuged $(12000 \mathrm{~g}$ for $15 \mathrm{~min})$ over $3 \mathrm{ml}$ Ficoll (Pharmacia, Sweden: $10 \% \mathrm{w} / \mathrm{v}$ ) in sodium chloride solution $(0.9 \% \mathrm{w} / \mathrm{v}$ ) after the method of Harrison (1976). Semen from straws frozen and thawed after storage in liquid nitrogen at $-196^{\circ} \mathrm{C}$ was similarly treated. The sedimented spermatozoa were re-suspended in phosphate-buffered saline (pH 6.9) and the ATP content was determined using a luciferin/luciferase test kit (Lumac, Postbus 1-B2450, Zolder, Belgium: Foulkes \& MacDonald, 1979). Two samples were assayed from each ejaculate.

\section{Morphological examination of spermatozoa}

C. Iular integrity. A sample $(0.1 \mathrm{ml})$ from each ejaculate was diluted with $0.1 \mathrm{ml}$ formal-citrate (trisc ium citrate $2 \mathrm{H}_{2} \mathrm{O}, 2.9 \mathrm{~g}$ and $0.1 \mathrm{ml} 40 \%$ formaldehyde made up to $100 \mathrm{ml}$ with deionized water; Dott \& Foster, 1975) immediately after collection. Two drops of the fixed semen were added to 8 drops of a nigrosin and eosin (G. T. Gurr, London) stain (Hancock, 1952). The test tube was mixed by gently rolling between the palms of the hands and, after exactly $5 \mathrm{~min}$, one drop was placed on each of two glass slides and smears were prepared. The smears were air-dried, mounted in DPX and 100 cells on each of the two slides were examined at random by two independent observers. The percentages of cells stained, unstained or partly stained were noted.

Sperm abnormalities. From each of the two smears prepared above, 100 cells were further examined for morphological abnormalities and these were recorded as a percentage of the total number of spermatozoa. Categories used were detached heads (A1), malformed heads (A2), abnormal acrosomes (A3), abnormal mid-pieces, including double tails (A4), bent tails (A5), coiled 
tails (A6), proximal protoplasmic droplets (A7) and distal protoplasmic droplets (A8). The number of detached droplets per 100 spermatozoa was also recorded (A9).

Nuclear vacuoles. Ejaculated semen $(0.1 \mathrm{ml})$ was diluted in $0.1 \mathrm{M}$-phosphate-saline $(0.9 \% \mathrm{w} / \mathrm{v})$, $\mathrm{pH} 7.0$, to give a concentration of $2.5 \times 10^{8}$ spermatozoa $/ \mathrm{ml}$. Aliquants $(0.1 \mathrm{ml})$ of the diluted semen were added to duplicate samples of (a) $1.0 \mathrm{ml}$ buffered formal-saline ( $40 \%$ formaldehyde, $1 \mathrm{ml}$ in $100 \mathrm{ml} 0 \cdot 1 \mathrm{M}$-phosphate-buffered saline) and (b) sodium dodecyl sulphate (SDS; $1 \% \mathrm{w} / \mathrm{v}$ ) in $0.05 \mathrm{M}$-borate buffer and incubated for $30 \mathrm{~min}$ at $30^{\circ} \mathrm{C}$. Buffered formal saline $(1 \mathrm{ml})$ was added to each preparation and smears were prepared on two glass slides. For each slide 100 spermatozoa were examined under phase-contrast microscopy and the proportion of cells with nuclear vacuoles was noted under four classes: apical (NV1), sub-apical (NV2), equatorial (NV3) and the total (NV4).

Acrosomal integrity. After cooling to $5^{\circ} \mathrm{C}$ but before freezing, samples of semen diluted for use in the field were placed on clean glass slides and a smear was prepared and air-dried. The smear was fixed by immersion in buffered formal saline, drained and stained with Giemsa solution in Sorenson's buffer, $\mathrm{pH} 7 \cdot 0$ (Watson, 1975). Slides were similarly prepared from two straws thawed after freezing and storage at $-196^{\circ} \mathrm{C}$. Two slides were prepared from each sample and 20 spermatozoa were examined on each. The integrity of the acrosome of each cell was estimated on a scale of $0-3$, with zero representing a normal, intact acrosome. The mean score for each slide was recorded.

Hyaluronidase. Two samples $(1 \mathrm{ml})$ of semen diluted in diluent for use in the field were centrifuged $(12000 \mathrm{~g}$ for $10 \mathrm{~min})$ at $20^{\circ} \mathrm{C}$ over $3 \mathrm{ml}$ of a solution of dextran $(6 \mathrm{~g})$ and raffinose $(15 \mathrm{~g})$ made up to $100 \mathrm{ml}$ in deionized water. The top $0.5 \mathrm{ml}$ of the supernatant was removed and diluted with 6 volumes of deionized water. Straws thawed after freezing and storage at $-196^{\circ} \mathrm{C}$ were similarly treated. The hyaluronidase activity present in the supernatant (seminal plasma) was determined using the procedure of Foulkes \& Watson (1975). The total hyaluronidase content of the sample was determined by freezing $\left(-196^{\circ} \mathrm{C}\right)$ and thawing $0.2 \mathrm{ml}$ of diluted semen 5 times and diluting with 25 volumes of deionized water. The concentration of hyaluronidase present in the separated seminal plasma and the whole sample were calculated and the proportion present in the seminal plasma was recorded as a measure of acrosomal damage.

Sperm head measurements. Slides prepared by the nigrosin-eosin procedure above were examined using a 'Quantimet' device (Dott \& Foster, 1978) and measurements were made of 10 sperm heads. Their length, width, area and the ratio of width to length were recorded, together with the area of the acrosome as a proportion of the whole head.

\section{Fertility measurements}

Non-return rates were obtained from 383 individual ejaculates using a nominal 40 doses of semen from each to provide a total of some 15320 inseminations. To avoid confounding ejaculate non-return rates with differences due to inseminating techniques, a factorial design was adopted in the field to allow 5 inseminators to use semen from 1 bull. The 40 doses were divided into parcels of 8 and parcels from 5 different bulls were issued to each inseminator taking part. A systematic layout was designed to distribute the bulls amongst as many inseminators as possible. The semen was used to inseminate Friesian cows at their first service after calving. The percentage reported as having not returned to service within 49 days ( 2 oestrous cycles plus two standard deviations; Wood, 1976) was used as a measure of the fertility of individual ejaculates. To avoid confounding results from ejaculates with seasonal variations in the reproductive performance of the cow population, each replicate of 5 inseminators was required to complete its 200 inseminations within 3 months, using doses in strict rotation to obtain widespread distribution amongst herds. The number of doses used in the field was restricted to 40 per ejaculate to minimize the effect of poor semen on the breeding programme of the co-operating farmers while still providing a reliable 
estimate of the non-return percentage. When replicates could not be completed, they were omitted from the statistical analysis to avoid any likelihood of bias.

\section{Statistical methods}

The repeatability of each semen assessment technique was defined as the correlation between duplicate measurements of the same sample attribute made by two technicians on the same sample or on two samples from the same ejaculate. When more than two estimates of the same variable were made all possible pairs were correlated. The discriminating power of a trait, or power for short, is the extent to which there was between-bull variation in respect to that trait and was that proportion (D) of total variations $\left(\sigma^{2}\right)$ attributable to variation amongst bulls free of other effects $\left(\sigma^{2} s\right)$, i.e. $D=\sigma^{2} s / \sigma^{2}$. For a trait to be useful as a predictor it should have both power (to discriminate between bulls) and repeatability.

The non-return rates were regressed by multiple regression with all the traits previously identified in groups according to power: a stepwise technique was employed (Wood, 1967). Regression equations obtained in this way were used to predict the expected non-return rate for each ejaculate after substitution with the value obtained for the trait measured. Tests wereperformed at each stage in the analysis to identify any bull or bulls whose semen characteristics were extreme enough to bias the result.

\section{Results}

\section{Fertility measures}

The mean volumes ( \pm s.e.m.) of the 647 first and 646 second ejaculates collected were $4.22 \pm 0.065$ and $4.08 \pm 0.053 \mathrm{ml}$ respectively. They were not significantly different but increased slightly with age over the period studied. A linear increase was observed amounting to $0 \cdot 10$ $( \pm 0.03)$ and $0.13( \pm 0.04) \mathrm{ml} /$ month respectively. The mean densities were $1650( \pm 25) \times 10^{6}$ and $1110( \pm 17) \times 10^{6}$ spermatozoa $/ \mathrm{ml}$ semen respectively and differed significantly $(P<0.001)$. Since the densities tended to decline by $24 \times 10^{6}$ and $56 \times 10^{6}$ spermatozoa/month there was little change in the overall production of spermatozoa, as previously reported by Carter, Wood \& Wright (1980) for a separate group of bulls.

All measurements made during the course of the study were regressed against the non-return rate determined for the ejaculates from the individual bulls. The mean non-return rates ( \pm s.e.m.) of the 242 first ejaculates and 141 second ejaculates used in the field were $63 \cdot 1( \pm 1 \cdot 1) \%$ and $68 \cdot 3$ $( \pm 1.7) \%$ and were significantly different $(P<0.05)$. No significant interactions were found between the temperature of the housing facility and fertility. No significant trends in semen quality on non-return rate were identified during the time individual bulls were studied, although the motilities and non-return rates of initial ejaculates studied for each bull tended to be depressed. The regression technique identified one bull $(\mathrm{H} 16)$ as an outlier which increased the lower range of fertility and analyses were worked both including and excluding this bull. The repeatability of the various traits was not affected by the exclusion but the discriminating power of some was reduced. The values obtained for the power and repeatability of the various traits and their overall correlations with fertility (non-return rate) are given in Table 1 . The results of the regression analyses of potentially useful parameters against non-return rate are given in Table 2, including and excluding values from the outlying bull, H16. The relevant predictive equations derived from these traits are given below together with their multiple regression coefficients $(r)$ and the number of records employed $(n)$. 
Table 1. Coefficients of correlation between semen traits and non-return rate

\begin{tabular}{|c|c|c|c|c|c|}
\hline \multirow[b]{2}{*}{ Trait } & \multirow[b]{2}{*}{$\begin{array}{c}\text { Power } \\
(\%)\end{array}$} & \multirow[b]{2}{*}{$\begin{array}{c}\text { Repeatability } \\
(\%)\end{array}$} & \multicolumn{3}{|c|}{ Correlation coefficient } \\
\hline & & & $\begin{array}{c}\text { First } \\
\text { ejaculate }\end{array}$ & Combined & $\begin{array}{l}\text { Second } \\
\text { ejaculate }\end{array}$ \\
\hline \multicolumn{6}{|l|}{ Motility } \\
\hline Ejaculated (MI) & 24 & 76 & 0.43 & & $0 \cdot 39$ \\
\hline Diluted in saline (M2) & 32 & 83 & 0.51 & & 0.42 \\
\hline Thawed (M3) & 29 & 62 & 0.56 & & 0.56 \\
\hline Thawed (citrate) (M4) & 29 & 58 & 0.55 & & 0.55 \\
\hline Recovery after shearing (M5) & 10 & 58 & -0.43 & & $-0 \cdot 30$ \\
\hline Photographic $\left(5^{\circ} \mathrm{C}\right)(\mathrm{M} 6)$ & 26 & 46 & 0.32 & & 0.28 \\
\hline (thawed) (M7) & 18 & 32 & 0.29 & & $0 \cdot 29$ \\
\hline ATP content & 42 & & & 0.42 & \\
\hline \multicolumn{6}{|l|}{ Cellular integrity } \\
\hline Fully stained & 26 & 77 & -0.41 & & -0.42 \\
\hline Partly stained & 10 & 22 & 0.41 & & 0.40 \\
\hline Unstained & 25 & 77 & -0.09 & & 0.03 \\
\hline \multicolumn{6}{|l|}{ Abnormalities } \\
\hline Detached heads (A1) & 70 & 83 & $-0 \cdot 40$ & & -0.27 \\
\hline Malformed heads (A2) & 20 & 32 & -0.19 & & $-0 \cdot 16$ \\
\hline Abnormal acrosome (A3) & 31 & 29 & $-0 \cdot 16$ & & -0.04 \\
\hline Abnormal mid-pieces (A4) & 19 & 18 & -0.25 & & -0.03 \\
\hline Bent tails (A5) & 32 & 46 & $-0 \cdot 28$ & & $-0 \cdot 30$ \\
\hline Coiled tails (A6) & 85 & 77 & -0.51 & & -0.56 \\
\hline Proximal droplets (A7) & 27 & 71 & $-0 \cdot 31$ & & $-0 \cdot 30$ \\
\hline Distal droplets (A8) & 50 & 62 & -0.50 & & $-0 \cdot 51$ \\
\hline Detached droplets (A9) & 13 & 42 & -0.02 & & -0.03 \\
\hline \multicolumn{6}{|l|}{ Nuclear vacuoles } \\
\hline Apical (NV1) & 22 & 19 & & $0 \cdot 24$ & \\
\hline Sub-apical (NV2) & 38 & 58 & & $0 \cdot 20$ & \\
\hline Equatorial (NV3) & 20 & 0 & & 0.35 & \\
\hline Total (NV4) & 24 & 33 & & $0 \cdot 39$ & \\
\hline \multicolumn{6}{|l|}{ Acrosomal integrity } \\
\hline $5^{\circ} \mathrm{C}$ (G5) & 41 & 24 & -0.12 & & -0.12 \\
\hline Thawed (Gpt) & 40 & 71 & -0.13 & & -0.06 \\
\hline \multicolumn{6}{|l|}{ Hyaluronidase release } \\
\hline $5^{\circ} \mathrm{C}$ (H5) & 35 & 90 & -0.47 & & -0.40 \\
\hline Thawed (Hpt) & 27 & 90 & -0.32 & & -0.44 \\
\hline \multicolumn{6}{|l|}{ Sperm head measurements } \\
\hline Width & 28 & 77 & & 0.05 & \\
\hline Length & 30 & 89 & & $0 \cdot 27$ & \\
\hline Width/length & 38 & 89 & & $-0 \cdot 14$ & \\
\hline Area & 11 & 82 & & $0 \cdot 17$ & \\
\hline
\end{tabular}

\section{Motility and non-return rate}

Both motility after dilution in saline (M2) and motility after thawing and diluting in citrate (M4) were useful predictors of non-return rate with or without Bull H16 $(P<0.001)$. Excluding Bull H16, regression equations for predicting non-return rate for first (NR1) and second (NR2) ejaculates were:

$$
\begin{array}{lrl}
\mathrm{NR} 1 & =47 \cdot 9+0 \cdot 2888 \mathrm{M} 2+0.3898 \mathrm{M} 4 & r=0 \cdot 5440 ; n=216) \\
\mathrm{NR} 2=58 \cdot 0+0.4930 \mathrm{M} 4 & (r=0.4642 ; n=129)
\end{array}
$$

With Bull H16 included, motility after thawing (M3) had increased value in predicting the fertility of first ejaculates:

$$
\mathrm{NR} 1=42 \cdot 7+0 \cdot 2622 \mathrm{M} 2+0 \cdot 2522 \mathrm{M} 3+0 \cdot 3845 \mathrm{M} 4
$$$$
(r=0 \cdot 5951 ; n=231)
$$

with an error of estimate of $11 \cdot 4 \%$ NR1. 
Table 2. Regression analyses of all traits having significance on non-return rate

\begin{tabular}{|c|c|c|c|c|c|c|c|c|}
\hline \multirow[b]{3}{*}{ Trait } & \multicolumn{4}{|c|}{ All bulls } & \multicolumn{4}{|c|}{ Bull H16 excluded } \\
\hline & \multicolumn{2}{|c|}{ First ejaculates } & \multicolumn{2}{|c|}{ Second ejaculates } & \multicolumn{2}{|c|}{ First ejaculates } & \multicolumn{2}{|c|}{ Second ejaculates } \\
\hline & $\mathrm{df}$ & MS & df & MS & $\mathrm{df}$ & MS & $\mathrm{df}$ & MS \\
\hline Motility (saline; M2) & 1 & 137 & 1 & 152 & 1 & $7878^{* * *}$ & - & - \\
\hline Motility (thawed; M3) & 1 & $1089^{* * *}$ & 1 & $1916^{* * *}$ & - & - & - & - \\
\hline Motility (citrate; M4) & 1 & $12152^{* * * *}$ & $i$ & 1 & - & - & 1 & $3148^{* * *}$ \\
\hline Abnormal midpiece (A4) & 1 & 43 & 1 & $i$ & - & - & - & - \\
\hline Bent tails (A5) & 1 & 8 & 1 & 19 & - & - & 1 & 244 \\
\hline Coiled tails (A6) & 1 & $6509^{* * *}$ & 1 & $6213^{* * *}$ & - & $\ldots$ & - & - \\
\hline Proximal droplets (A7) & 1 & $851^{* *}$ & 1 & $754^{* *}$ & 1 & $690^{*}$ & 1 & $527^{*}$ \\
\hline Distal droplets (A8) & 1 & 75 & 1 & 103 & $\therefore$ & - & 1 & 56 \\
\hline Acrosomal integrity $\left(5^{\circ} \mathrm{C} ; \mathrm{G} 5\right)$ & 1 & 247 & 1 & $396^{*}$ & - & - & 1 & 176 \\
\hline Hyaluronidase release $\left(5^{\circ} \mathrm{C} ; \mathrm{H} 5\right)$ & 1 & 2 & 1 & 18 & 1 & 202 & - & - \\
\hline Residual variation & 202 & 104 & 112 & 95 & 206 & 114 & 119 & 70 \\
\hline
\end{tabular}

$* P<0.05 ; * * P<0.01 ;{ }^{* * *} P<0.001$.

\section{ATP concentrations and non-return rate}

ATP concentrations in spermatozoa after thawing were available from 66 first and 33 second ejaculates from 12 bulls and were significantly correlated with fertility for only the first ejaculates:

$\mathrm{NR} 1=1.08 \mathrm{ATP}-20 \cdot 1$

$$
(r=0 \cdot 42 ; n=66)
$$

\section{Morphology and non-return rate}

Regression analysis showed that proximal protoplasmic droplets (A7) had similar predictive power both with and without the contribution of Bull H16 $(P<0.001)$. Distal protoplasmic droplets (A8) remained useful in first ejaculates $(P<0.001)$ when Bull $\mathrm{H} 16$ was excluded and abnormal mid-pieces (A4) were significant $(P<0.05)$ when data from Bull $\mathrm{H} 16$ were included. Predictive equations without Bull $\mathrm{H} 16$ were:

$$
\begin{array}{ll}
\mathrm{NR} 1=72.0-0.5098 \mathrm{~A} 7-0.6428 \mathrm{~A} 8 & (r=0.3920 ; n=221) \\
\mathrm{NR} 2=73.8-0.5918 \mathrm{~A} 7 & (r=0.3501 ; n=133)
\end{array}
$$

Traits that were identified as having high power of discrimination between bulls were the percentage of spermatozoa with coiled tails (A6), hyaluronidase release at $5^{\circ} \mathrm{C}(\mathrm{H} 5)$, acrosomal integrity at $5^{\circ} \mathrm{C}(\mathrm{G} 5)$ and hyaluronidase release after thawing $\left(\mathrm{H}_{\mathrm{pt}}: P<0.001\right)$. Removal of data from $\mathrm{H} 16$ eliminated coiled tails and reduced the value of the others although hyaluronidase release at $5^{\circ} \mathrm{C}$ remained effective $(P<0.001)$ in the first ejaculate. The relevant equations without Bull $\mathrm{H} 16$ were:

$$
\begin{array}{ll}
\mathrm{NR} 1=71 \cdot 0-0.2080 \mathrm{H} 5 & (r=0.3094 ; n=195) \\
\mathrm{NR} 2=82.8-0.5063 \mathrm{~A} 5-5.25 \mathrm{G} 5 & (r=0.3658 ; n=115)
\end{array}
$$

With Bull $\mathrm{H} 16$ included the regression equations were:

$$
\begin{array}{ll}
\mathrm{NR} 1=80.7-0.8266 \mathrm{~A} 6-5.87 \mathrm{G} 5-0.1620 \mathrm{H} 5 & (r=0.5937 ; n=121) \\
\mathrm{NR} 2=88.0-1.1283 \mathrm{~A} 6-6.46 \mathrm{G} 5-0.1604 \mathrm{H}_{\mathrm{pt}} & (r=0.6400 ; n=121)
\end{array}
$$

\section{Sperm head measurements}

The regression analysis of non-return rate on sperm head measurements was conducted after combining information from first and second ejaculates. The sperm heads of Bull H16 were shorter 
than those of other bulls and, since Bull $\mathrm{H} 16$ was of low fertility, resulted in a positive correlation: when he was excluded no useful relationship remained.

\section{Nuclear vacuoles and non-return rate}

Information obtained from first and second ejaculates were combined and the incidence of nuclear vacuoles was examined. The percentage of vacuoles in the equatorial region (NV3) was positively related to non-return rate $(P<0.05)$. With Bull $\mathrm{H} 16$ excluded the regression equation was:

$$
\mathrm{NR}=63.9+8.6 \mathrm{NV} 3 \quad(r=0.3337 ; n=49)
$$

and with Bull H16 included:

$$
\mathrm{NR}=57 \cdot 8+14 \cdot 2 \mathrm{NV} 3 \quad(r=0 \cdot 3465 ; n=60)
$$

\section{Combined measures and non-return rate}

All semen characteristics found to be significantly useful in predicting the non-return rate (Table 3) were combined in a single analysis both with and without information from Bull H16. Since many characters showed intercorrelations many traits that were significant in the individual analyses dropped out leaving motility after dilution in saline (M2) and motility after freezing and thawing (M3), percentage of cells with coiled tails (A6; only when Bull $\mathrm{H} 16$ was included) and the percentage of proximal protoplasmic droplets (A7) as the principal predictors. Since it will not always be possible to obtain two ejaculates or to freeze semen before making a decision on the suitability of a bull for use in $\mathrm{Al}$, data from first and second ejaculates were combined and the regressions computed twice, once with all traits and once with the useful characteristics measurable on ejaculated semen. In this analysis, distal protoplasmic droplets (A8) re-assumed significance when Bull $\mathrm{H} 16$ was excluded due to different levels in the first and second ejaculates. The predictive equations using data from all bulls were:

(i) for all traits: $\mathrm{NR}=55 \cdot 3+0.2194 \mathrm{M} 2+0.3634 \mathrm{M} 3-0.7737 \mathrm{~A} 6-0.3173 \mathrm{~A} 7$

$$
(r=0.6642 ; n=367)
$$

(ii) for traits of ejaculated semen: $\mathrm{NR}=57 \cdot 5+0 \cdot 3763 \mathrm{M} 2-0.8702 \mathrm{~A} 6-0.3328 \mathrm{~A} 7$

$$
(r=0.6341 ; n=373)
$$

With data from Bull $\mathrm{H} 16$ excluded the equations were:

(iii) For all traits: $\mathrm{NR}=56.5+0.2061 \mathrm{M} 2+0.3315 \mathrm{M} 3-0.2955 \mathrm{~A} 7-0.2176 \mathrm{~A} 8$

$$
(r=0 \cdot 5174 ; n=346)
$$

(iv) For traits of ejaculated semen: $\mathrm{NR}=58.8+0.3446 \mathrm{M} 2-0.3087 \mathrm{~A} 7-0.2619 \mathrm{~A} 8$

$$
(r=0.4753 ; n=352)
$$

The standard errors of estimate for these equations were $10.5 \% \mathrm{NR}$ compared with values in the range $10-14 \%$ NR for all equations developed above.

These four equations (i-iv) were used to compute the non-return rates to be expected from each of the 1293 ejaculates collected from the bulls in the course of the trial. An arbitrary 'acceptable' threshold non-return rate of $70 \%$ was chosen and the proportion of ejaculates from each bull that had predicted non-return rates greater than this was calculated to determine the probability of acceptance of each bull when individual ejaculates were examined (Table 4). The usefulness of the equations was judged by comparing the rank order of their observed non-return rates in the field with the rank order of the predicted probability of acceptance for each bull (Table 4). Spearman's rank correlation coefficients were calculated and were $0.76,0.83,0.74$ and 0.82 for the four predictive equations (i-iv) respectively. 


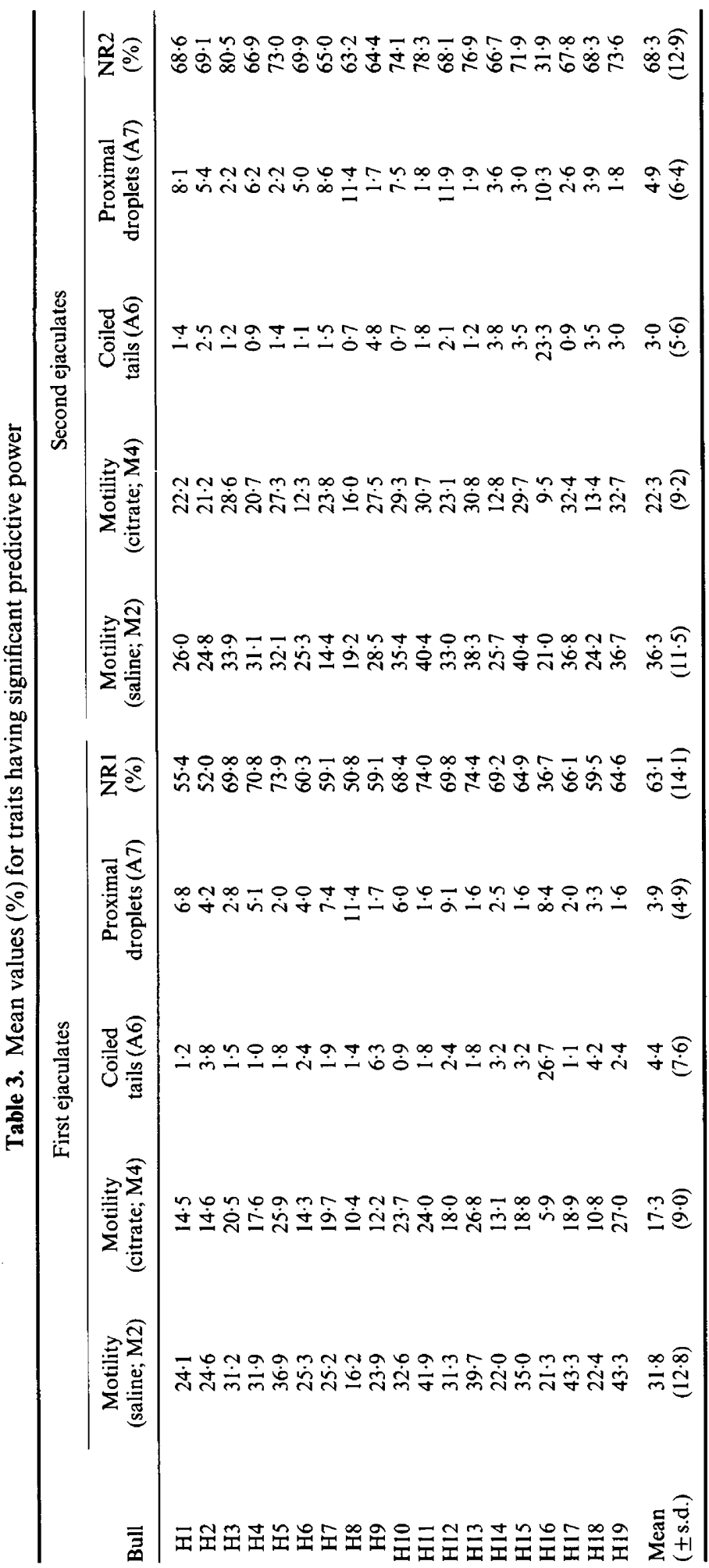




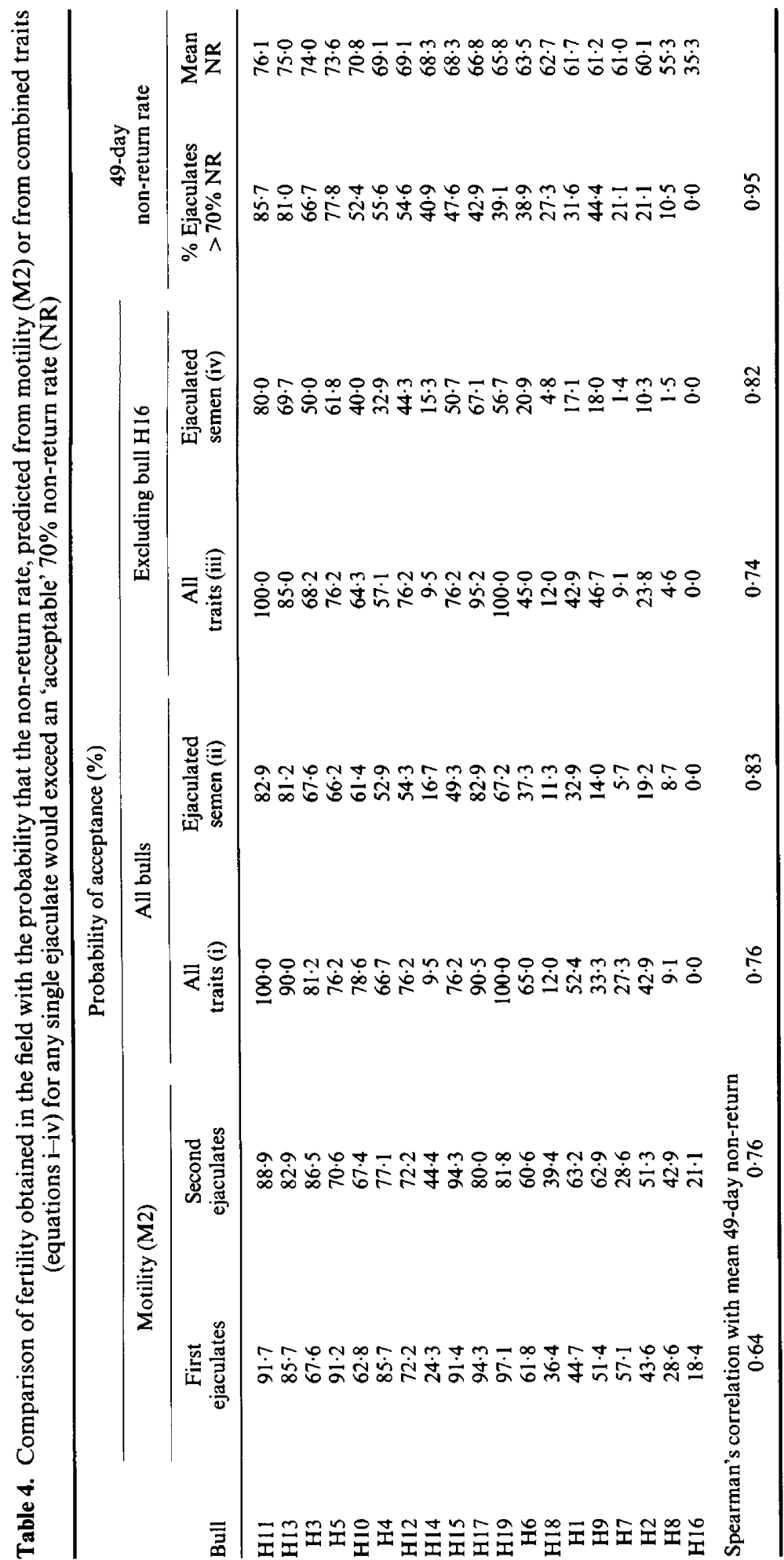




\section{Discussion}

The primary purpose of this trial was to determine the extent to which laboratory measures of semen quality employed in the selection of animals for AI reflected the actual fertility of Hereford bulls when used in AI. This information is not normally available since clearly the fertility of sires rejected by these criteria is never established. Information obtained from sires that are accepted and used for $\mathrm{Al}$ is of little value since semen is used in the field only after laboratory examination and rejection of a proportion of ejaculates, so that no fertility data can be gathered. Since such ejaculates are discarded on the basis of the general assumption that low fertility would result from their use, it was an imperative that the economic disadvantage to the farmers in this trial on whose cows the semen was to be used be limited and this was done by restricting the number of inseminations from any one ejaculate to a maximum of 40 . This will have increased the error associated with the result for each individual ejaculate (Foote \& Oltenacu, 1980) but the use of 18-22 ejaculates per bull ensured that a representative and more accurate measure of a bull's individual fertility was obtained. The use of this number of ejaculates allowed a good measure of the extent of variation and repeatability of the measurements of semen traits within bulls to be made and allowed their power of discrimination between bulls to be measured. This was increased by the availability of measurements of some characters (e.g. volume, density, motility after dilution in saline and percentage of cells with abnormalities) from those ejaculates collected but not used in the field trial.

One fundamental result of the trial was the identification of the range of non-return rates $(35.3-76 \cdot 1 \%$; Table 4$)$ that would result from the indiscriminate use of semen from Hereford bulls reared at MLC Performance Testing Stations for AI. Since, in commercial practice, all semen is subject to semen assessment before being released for use in AI, this range would have been reduced in normal circumstances and the majority of bulls produced at least some semen that would have passed these criteria and so have obtained some better level of fertility. This would have resulted, however, in a considerable reduction in the productivity of those bulls with lower semen quality from which much semen would have been discarded. The proportion of ejaculates from each bull that needed to be discarded to obtain acceptable fertility may be inferred from the percentage of ejaculates that had a non-return greater than $70 \%$ (Table 4).

Ten of the traits investigated in this trial had significant value as predictors of fertility (Table 3) although motility after thawing and the proportion of cells with abnormal mid-pieces were of use only if data from the outlying low fertility Bull $\mathrm{H} 16$ were included. The useful characteristics were those which described motility before and after freezing, spermatozoa with abnormalities likely to inhibit movement and damaged and immature spermatozoa. The proportion of spermatozoa with detached heads did not have great predictive power despite previous evidence identifying this character as one resulting in infertility in 8 Hereford bulls used for natural service (Williams, 1965). In that work, ejaculates exhibited $39 \cdot 2-93.7 \%$ of cells with the abnormality. In the current study, the range in mean values for the 19 bulls was $2 \cdot 3-36 \cdot 7 \%$ in the first and $2 \cdot 7-36.9 \%$ in the second ejaculates. The worst bull $(\mathrm{H} 2)$ had a range between 3 and $73 \%$ for individual ejaculates and ranked 17 in order of fertility (Table 4).

The correlations obtained between results from semen assessment techniques and non-return rates were much lower within bulls than between bulls, so that prediction of bull fertility would be more reliable than prediction of the fertility of individual ejaculates. This is in line with a previous study (Foote \& Oltenacu, 1980) in which it was shown that culling of bulls would have a greater effect on fertility than selection of ejaculates. For the purposes of this trial, however, in which the value of semen assessment techniques in predicting the overall fertility of a bull was at issue, a bull could only be assessed on the basis of the ejaculates he produced. Stepwise multiple regression analyses revealed interdependencies amongst the traits with individual values as predictors of fertility. When these are discounted, motility after dilution in saline, motility after thawing and the percentage of cells with coiled tails or proximal protoplasmic droplets were left as predictors. The predictive equations derived from the fertility data obtained with the 383 ejaculates used in the field 
may be applied to any one of the 1293 ejaculates produced by the bulls since each can be considered as representing that bull's semen quality. Each ejaculate can thus be given a predicted non-return rate and the proportion of these greater than some arbitrary acceptable level (e.g. $70 \%$ ) estimated (Table 4). This procedure will only have value if it reflects the observed non-return rate of the bull. A bull with a high observed non-return rate would be expected to exhibit a high probability of acceptance for any ejaculate examined: thus the Spearman's correlations of the rank orders of non-return rate and probability of acceptance should be high. The rank correlations obtained with results from the predictive equations using characters available in ejaculated semen (i and iii) were 0.83 and 0.82 respectively. These had therefore ranked the bulls more accurately than the best of the equations using a single trait, i.e. motility after diluting in saline (M2) which showed coefficients of 0.64 and 0.76 when first or second ejaculates were examined. The rank correlation coefficients $(0.76$ and 0.73$)$ obtained with the equations based on characters available when semen was frozen and thawed (i.e. all traits) were lower than those from ejaculated semen since only 383 ejaculates were frozen and thawed as opposed to 1293 semen samples collected, the smaller number increasing the variability of the proportion of ejaculates from any one bull exceeding a predicted non-return rate of $70 \%$. As might be expected the proportion of ejaculates from each bull that had non-return rates determined in the field trial of greater than $70 \%$ correlated very closely with the overall observed fertility of the bulls $(r=0.95$; Table 4$)$.

The indifferent ability of semen characteristics to predict non-return rates has been known and discussed for many years. Salisbury \& VanDemark (1961) proposed that there will be an asymptotic relationship between any semen trait and fertility: a characteristic may provide a prediction of non-return rate until some threshold is reached. This situation is exacerbated by the practice of commercial AI centres of using an excess number of spermatozoa to provide insurance against reduced fertility or damage during processing and storage. Reductions in the viability of individual spermatozoa will be masked by the remaining competent cells. For this reason, in a trial in which different numbers of spermatozoa were included in each insemination straw, Pace, Sullivan, Elliott, Graham \& Coulter (1981) found fertility to correlate not with the percentage of viable cells but only with the total number of surviving cells. This was not relevant to the interpretation of results in this trial since all insemination straws contained $20 \times 10^{6}$ spermatozoa and so the percentage of cells with any characteristic will have correlated exactly with the number of spermatozoa. It remains true, however, that strong correlations will not be identified between semen characteristics and fertility if sufficient spermatozoa are included to compensate for their effects.

The standard errors of estimate for the non-return rate predicted using the equations above for any one ejaculate were about $10.5 \%$ so that the confidence intervals $(P=0.05)$ would be around $21 \%$. This is inversely proportional to the square root of the number of ejaculates examined so that to improve the confidence interval to even $10 \%$ non-return would require 5 ejaculates to be examined. It would clearly not be sufficient to examine single ejaculates when seeking to evaluate suitability of a Hereford bull for use in AI and the situation would be worse if any one of the semen characteristics were considered in isolation. The finding that the second of two ejaculates collected on one day had a significantly higher fertility than the first (68.3 vs $63 \cdot 1 \%$ non-return rate) also suggests that bull selection procedures should be reviewed.

We are particularly grateful to Mr R. G. Goodey, Mr O. D. John and other staff at the Reading Cattle Breeding Centre for their painstaking work in obtaining the data presented here. The late Professor J. L. Hancock, Dr H. M. Dott and Dr P. F. Watson conducted the measurements on nuclear vacuoles, sperm head size and Giemsa staining respectively.

\section{Referenences}

Carter, A.P., Wood, P.D.P. \& Wright, P.A. (1980) Association between scrotal circumference, live weight and sperm output in cattle. J. Reprod. Fert. $59,447-451$.
Cox, C.P. \& Melrose, D.R. (1953) The calibration of a photo-electric absorptiometer for the rapid estimation of counts of spermatozoa in bull semen. J. agric. Sci., Camb. 43, 375-379. 
Dott, H.M. \& Foster, G.C.A. (1975) Preservation of differential staining of spermatozoa by formalcitrate. J. Reprod. Fert. 45, 57-60.

Dott, H.M. \& Foster, G.C.A. (1978) The estimation of sperm motility in semen, on a membrane slide, by measuring the area change frequency with an image analysing computer. J. Reprod. Fert. 55, 161-166.

Foote, R.H. \& Oltenacu, E.A.B. (1980) Increasing fertility in AI by culling bulls or ejaculates within bulls. Proc. 8th Tech. Conf. AI and Reprod. 6-11.

Foulkes, J.A. \& MacDonald, B.J. (1979) The relationship between ATP content and motility of bovine spermatozoa. Theriogenology 11, 313-319.

Foulkes, J.A. \& Watson, P.A. (1975) Hyaluronidase activity in seminal plasma as a method of assessing bull sperm integrity. J. Reprod. Fert. 43, 349-353.

Foulkes, J.A., Goodey, R.G. \& Stewart, D.L. (1977) Fertility of bovine semen frozen in four diluents for use in artificial insemination. Vet. Rec. 101, 171.

Glover, F.A. (1968) Physical methods of measuring the motility of bull spermatozoa. Nature, Lond. 219 , 1263-1264.

Hancock, J.L. (1952) The morphology of bull spermatozoa. J. exp. Biol. 29, 445-453.

Harrison, R.A.P. (1976) Highly efficient method for washing mammalian spermatozoa. J. Reprod. Fert. 48, 347-353.
Katz. D.F. \& Dott, H.M. (1975) Method of measuring swimming speed of spermatozoa. J. Reprod. Fert. 45, 263-272.

Linford, E., Glover, F.A., Bishop, C. \& Stewart, D.L. (1974) The relationship between semen evaluation methods and fertility in the bull. J. Reprod. Fert. 46, 283-291.

Pace, M.M., Sullivan, J.J., Elliott, F.I., Graham, E.F. \& Coulter, G.H. (1981) Effects of thawing temperature, number of spermatozoa and spermatozoa equality on fertility of bovine spermatozoa packaged in $0.5 \mathrm{ml}$ french straws. J. Anim. Sci. 53, 693-701.

Salisbury, G.W. \& VanDemark, N.L. (1961) Physiology of Reproduction and Artificial Insemination of Cattle. W. H. Freeman \& Co., San Francisco.

Watson, P.F. (1975) Use of Giemsa stain to detect changes in acrosomes of frozen ram spermatozoa. Vet. Rec. 97, 12-15.

Williams, G. (1965) An abnormality of the spermatozoa of some Hereford bulls. Vet. Rec. 77, 1204-1206.

Wood, P.D.P. (1967) A computational method of estimating variance components from non-orthogonal data in a mixed model. The Statistician 17, 307-314.

Wood, P.D.P. (1976) A note on the detection of oestrus in cattle bred by artificial insemination and the measurement of embryonic mortality. Anim. Prod. 22, 275-278. 